\title{
Blocking integrin $\beta 1$ decreases adhesion in chemoresistant urothelial cancer cell lines
}

\author{
STEFAN VALLO ${ }^{1,2}$, JOCHEN RUTZ ${ }^{2}$, MIRIAM KAUTSCH ${ }^{1,2}$, RIA WINKELMANN $^{3}$, MARTIN MICHAELIS $^{4}$, \\ FELIX WEZEL $^{5}$, GEORG BARTSCH ${ }^{2,6}$, AXEL HAFERKAMP ${ }^{2,6}$, FLORIAN ROTHWEILER ${ }^{1}$, \\ ROMAN A. BLAHETA ${ }^{2}$ and JINDRICH CINATL JR ${ }^{1}$ \\ ${ }^{1}$ Institute of Medical Virology; ${ }^{2}$ Department of Urology; ${ }^{3}$ Dr. Senckenberg Institute of Pathology, \\ University Hospital Frankfurt, D-60596 Frankfurt am Main, Germany; ${ }^{4}$ School of Biosciences, \\ University of Kent, Canterbury CT2 7NZ, UK; ${ }^{5}$ Department of Urology, University Hospital Ulm, \\ D-89081 Ulm; ${ }^{6}$ Department of Urology, University of Medicine, D-55131 Mainz, Germany
}

Received September 19, 2016; Accepted August 3, 2017

DOI: $10.3892 / \mathrm{ol} .2017 .6883$

\begin{abstract}
Treatment failure in metastatic bladder cancer is commonly caused by acquisition of resistance to chemotherapy in association with tumor progression. Since alterations of integrins can influence the adhesive and invasive behaviors of urothelial bladder cancer cell lines, the present study aimed to evaluate the role of integrins in bladder cancer cells with acquired resistance to standard first-line chemotherapy with gemcitabine, and cisplatin. Therefore, four gemcitabineand four cisplatin-resistant sublines out of a panel of four parental urothelial bladder cancer cell lines (TCC-SUP, HT1376, T24, and 5637) were used. Expression of integrin subunits $\alpha 3, \alpha 5, \alpha 6, \beta 1, \beta 3$, and $\beta 4$ was detected using flow cytometry. Adhesion and chemotaxis were analyzed. For functional assays, integrin $\beta 1$ was attenuated with a blocking antibody. In untreated cells, chemotaxis was upregulated in 3/4 gemcitabine-resistant sublines. In cisplatin-resistant cells, chemotaxis was enhanced in $2 / 4$ cell lines. Acquired chemoresistance induced the upregulation of integrin $\beta 1$ in all four tested gemcitabine-resistant sublines, as well as an upregulation in 3/4 cisplatin-resistant sublines compared with parental cell lines. Following the inhibition of integrin $\beta 1$, adhesion to extracellular matrix components was downregulated in $3 / 4$ gemcitabine-resistant sublines and in all four tested cisplatin-resistant sublines. Since integrin $\beta 1$ is frequently upregulated in chemoresistant urothelial cancer cell lines and inhibition of integrin $\beta 1$ may influence adhesion, further studies are warranted to evaluate integrin $\beta 1$ as a potential therapeutic target for bladder cancer in vivo.
\end{abstract}

Correspondence to: Dr Jindrich Cinatl Jr, Institute of Medical Virology, University Hospital Frankfurt, Paul-Ehrlich-Str. 40, D-60596 Frankfurt am Main, Germany

E-mail: cinatl@em.uni-frankfurt.de

Key words: adhesion, acquired resistance, cancer cell line collection, chemotaxis, cisplatin, gemcitabine, integrin $\beta 1$, urothelial cancer

\section{Introduction}

Urothelial cancer of the bladder is the 4th most commonly diagnosed cancer in men worldwide (1). Patients with metastatic disease are often treated with a combination chemotherapy containing gemcitabine and cisplatin as a standard of care $(2,3)$. However, the treatment success is limited, resulting in a median survival of 12-15 months. Treatment failure is commonly caused by acquired resistance after primary response $(2,3)$. Therefore, efficient second line chemotherapies are urgently needed.

Integrins have been identified to play an important role in the development of resistance to chemotherapy in bladder cancer (4). These molecules are transmembrane receptors with two different chains, an $\alpha$ (alpha) and a $\beta$ (beta) subunit. Integrins are bridges for cell-cell and cell-extracellular matrix (ECM) interactions. Cell-matrix contact plays a fundamental role in the metastatic potential of tumors (5). Alterations of integrin expression may result in an enhanced adhesive behavior in bladder cancer (6). Moreover, the expression patterns of integrin subtypes are known to be important mediators of tumor cell de-differentiation and tumor proliferation (7). Furthermore, it was shown that integrins were involved in the development of metastasis and recurrence of urothelial cancer $(6,8,9)$.

Drug-adapted cancer cell lines have been successfully used to study cancer cell resistance mechanisms $(10,11)$. To reflect the heterogeneity of individual bladder cancer patients and to enable a systematic evaluation of the role of integrins concerning resistance acquisition, we used a panel of 12 urothelial cancer cell lines consisting of 4 parental chemosensitive cell lines and their sublines with acquired resistance to gemcitabine or cisplatin $(12,13)$.

\section{Materials and methods}

Drugs. Cisplatin was purchased from Gry-Pharma (Kirchzarten, Germany), gemcitabine from Lilly (Bad Homburg, Germany).

Cell lines. The cell lines 5637, T24, HT1376, and TCC-SUP were obtained from the American Type Culture Collection 
(Manassas, VA, USA). The following drug-resistant sublines were established by continuous exposure to increasing drug concentrations as described previously $(12,14)$ and are part of the Resistant Cancer Cell Line (RCCL) collection (www.kent .ac.uk/stms/cmp/RCCL/RCCLabout.html): $5637^{\mathrm{r}} \mathrm{CDDP}^{1000}$ (cisplatin-resistant, $1,000 \mathrm{ng}$ cisplatin $/ \mathrm{ml}$ ), $5637^{\mathrm{r}} \mathrm{GEMCI}^{20}$ (gemcitabine-resistant, $20 \mathrm{ng}$ gemcitabine/ml), T24 ${ }^{\mathrm{r}} \mathrm{CDDP}^{1000}$, T2 ${ }^{\mathrm{r}} \mathrm{GEMCI}^{20}, \mathrm{HT}_{1376}{ }^{\mathrm{r}} \mathrm{CDDP}^{1000}$, HT $1376^{\mathrm{r}} \mathrm{GEMCI}^{20}$, TCC-SUP ${ }^{r} C_{D D P}{ }^{1000}$, and TCC-SUP ${ }^{\mathrm{T}} \mathrm{GEMCI}^{20}$. All cell lines were grown in Iscove's modified Dulbecco's medium supplemented with $10 \%$ fetal calf serum (FCS; Gibco, Karlsruhe, Germany), $100 \mathrm{IU} / \mathrm{ml}$ penicillin, and $100 \mu \mathrm{g} / \mathrm{ml}$ streptomycin at $37^{\circ} \mathrm{C}$. Cell line authentication was performed by short tandem repeat profiling.

Cell adhesion to extracellular matrix components. 24-well plates were coated with extracellular matrix components (Matrigel; Corning, Amsterdam, The Netherlands) overnight. Plates were washed with $1 \%$ bovine serum albumin (BSA) in phosphate buffered saline (PBS) to block nonspecific cell adhesion. Thereafter, $0.5 \times 10^{6}$ tumor cells were added to each well for $60 \mathrm{~min}$. Subsequently, non-adherent tumor cells were washed off. The adherent cells were fixed with $1 \%$ glutaraldehyde and counted in five different fields using a microscope (20x objective) to calculate the mean cellular adhesion rate.

Chemotaxis. Serum induced cell migration was examined using 6-well transwell chambers (Greiner, Frickenhausen, Germany) with $8 \mu \mathrm{m}$ pores. To evaluate cell migration, cells were placed in the upper chamber for $20 \mathrm{~h}$ in serum-free medium. The lower chamber contained $10 \%$ serum. After incubation, the upper surface of the transwell membrane was wiped gently with a cotton swab to remove non-migrating cells. Cells migrating to the lower surface of the membrane were stained using hematoxylin and counted. Cells migrating into the lower chamber were counted separately under the microscope.

Blocking study. Cells were preincubated for $60 \mathrm{~min}$ with a function-blocking anti-integrin $\beta 1$ monoclonal antibody $(20 \mathrm{mg} / \mathrm{l})$ (MAB 2253Z; MerckMillipore, Darmstadt, Germany). Controls remained untreated. Adhesion and chemotaxis was tested as indicated above.

Flow cytometry. Cells were washed in blocking solution (PBS, $0.5 \% \mathrm{BSA}$ ) and then incubated for $60 \mathrm{~min}$ at $4^{\circ} \mathrm{C}$ with phycoerythrin (PE)-conjugated monoclonal antibodies directed against the following integrin subtypes: Anti- $\alpha 3$ (IgG1; clone C3II.1), anti- $\alpha 5$ (IgG1; clone IIA1), anti- $\alpha 6$ (IgG2b, clone MP 4F10), anti- $\beta 1$ (IgG1; clone MAR4), anti- $\beta 3$ (IgG1; clone VI-PL2) or anti- $\beta 4$ (IgG2a; clone 439-9B; all: BD Biosciences, Heidelberg, Germany). Integrin expression was measured by flow cytometry (FACSCalibur; BD Biosciences, Heidelberg, Germany). Mouse IgG1-PE (MOPC-21) or mouse IgG2a-PE (G155-178; all: BD Biosciences) antibodies were used as isotype control.

Immunohistochemistry. 33 cases of invasive and non-invasive bladder cancers as well es corresponding normal urothelium were taken from the archive of the Dr. Senckenberg Institute of Pathology in Frankfurt. Tissue sections were stained for Integrin $\beta 1$, (D2E5) Rabbit mAb, Cell Signaling Technology
(Waltham, MA, USA), dilution 1:100. In brief, $4 \mu \mathrm{m}$ sections were cut and pretreated with Trilogy ${ }^{\mathrm{TM}}$, Cell Marcque (Rocklin, CA, USA), incubated with the antibody, antigen retrieval was performed at $\mathrm{pH} 6$ in a microwave oven using the Peroxidase-FLEX EnVision kit (Dako, Jena, Germany).

A pathologist, who was blinded to clinical history and therapeutic response, scored the immunohistochemical staining using a five-stage staining score: $0=$ negative; $1=$ weak; 2=moderate; 3 =strong; $4=$ =ery strong.

Images were acquired using a digital slide scanner (ScanScope XT; Aperio, Vista, CA, USA).

Statistical analysis. Results are expressed as mean \pm SD of at least three independent experiments. For statistical analysis student's t-test, analysis of variance (ANOVA), and Student-Newman-Keuls-Test were performed whenever applicable. $\mathrm{P}<0.05$ was considered to indicate a statistically significant difference.

\section{Results}

Influence of acquired resistance on adhesion to extracellular matrix components. In untreated cells, adhesion to extracellular matrix components was decreased in 2 of 4 gemcitabine-resistant sublines $\left(\mathrm{HT} 1376^{\mathrm{r}} \mathrm{GEMCI}^{20}\right.$ and TCC-SUP ${ }^{\mathrm{r}} \mathrm{GEMCI}^{20}$ ) and upregulated in 2 of 4 cell lines $\left(\mathrm{T} 24^{\mathrm{r}} \mathrm{GEMCI}^{20}\right.$ and $5637^{\mathrm{r}} \mathrm{GEMCI}^{20}$ ) compared to parental cells. In cisplatin-resistant sublines, adhesion was decreased in 1 of 4 cisplatin-resistant sublines (TCC-SUP ${ }^{\mathrm{r}} \mathrm{CDDP}^{1000}$ ) and enhanced in 2 cell lines $\left(\mathrm{HT} 1376^{\mathrm{r}} \mathrm{CDDP}^{1000}\right.$ and $5637^{\mathrm{r}} \mathrm{CDDP}^{1000}$ ) (Fig. 1).

Influence of acquired chemoresistance on chemotaxis. Chemotaxis was enhanced in 3 of 4 gemcitabine-resistant urothelial cancer cell lines (gemcitabine-resistant sublines of TCC-SUP, HT1376 and T24). In cisplatin-resistant

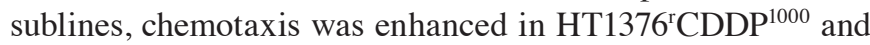
$\mathrm{T}_{2} 4^{\mathrm{r}} \mathrm{CDDP}^{1000}$ compared to parental cell lines (Fig. 2).

Differential expression of cell surface integrins. Expression of integrins on the cell surface was analyzed by flow cytometry (Fig. 3). In gemcitabine-resistant sublines, the expression of integrin $\alpha 3$ was enhanced in 3 sublines (gemcitabine-resistant sublines of T24, 5637, and TCC-SUP) and diminished in HT1376 ${ }^{\mathrm{r}} \mathrm{GEMCI}^{20}$ compared to parental cell lines. Integrin $\beta 1$ expression was upregulated in all gemcitabine-resistant sublines compared to parental cells. Integrin $\beta 4$ expression was enhanced in TCC-SUP ${ }^{\mathrm{r}} \mathrm{GEMCI}^{20}$ and diminished in $\mathrm{T} 24^{\mathrm{r}} \mathrm{GEMCI}^{20}$ and in $5637^{\mathrm{r}} \mathrm{GEMCI}^{20}$.

Comparing cisplatin-resistant cell lines, Integrin $\alpha 3$ expression was upregulated in 3 of 4 sublines (cisplatin-resistant sublines of T24, 5637, and TCC-SUP) and downregulated

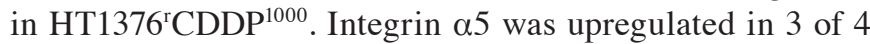
sublines (cisplatin-resistant sublines of 5637, TCC-SUP, and HT1376). Integrin $\beta 1$ expression was upregulated in 3 of 4 sublines (cisplatin-resistant sublines of HT1376, T24, and 5637) and downregulated in TCC-SUP ${ }^{\mathrm{r}} \mathrm{CDDP}^{1000}$. Integrin $\beta 4$

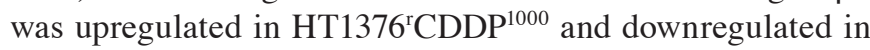
all other tested sublines (cisplatin-resistant sublines of T24, 5637, and TCC-SUP). 


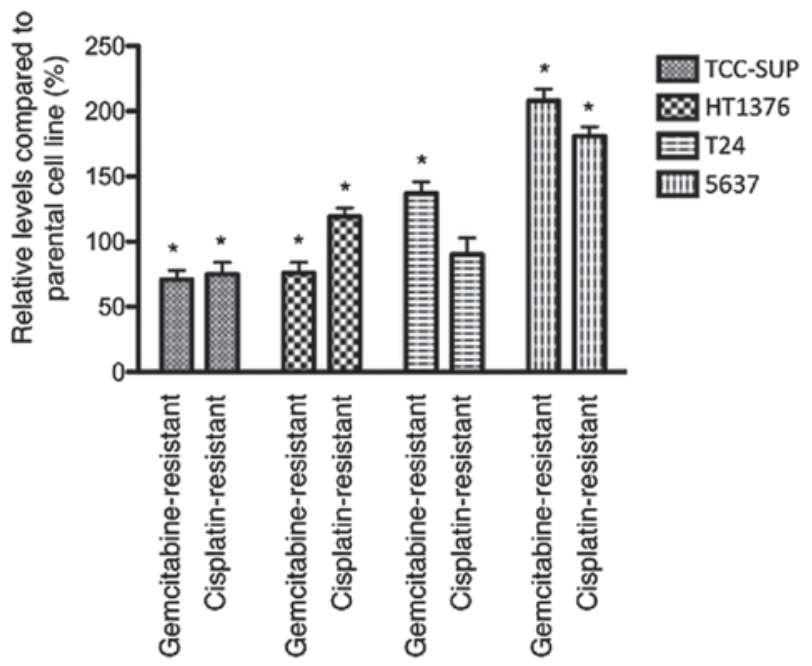

Figure 1. Evaluation of cell adhesion. Comparison of adhesive behavior of parental bladder cancer cell lines as well as of their gemcitabine- and cisplatin-resistant sublines. The plates were coated with extracellular matrix components overnight. Plates were washed with $1 \%$ BSA in PBS to block nonspecific cell adhesion. Thereafter, $0.5 \times 10^{6}$ tumor cells were added to each well for $60 \mathrm{~min}$. Subsequently, non-adherent tumor cells were washed off. The adherent cells were fixed with $1 \%$ glutaraldehyde and counted in five different fields using a microscope (20x objective) to calculate the mean cellular adhesion rate. Adhesion of parental cell lines was set as $100 \%$. ${ }^{*} \mathrm{P} \leq 0.05$ vs. controls.

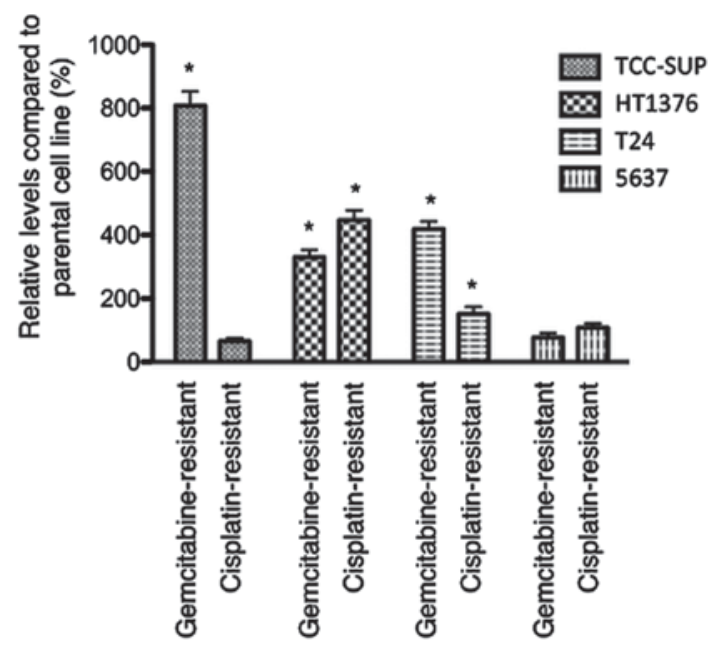

Figure 2. Evaluation of chemotaxis. Serum-induced chemotactic movement was examined using six-well transwell chambers with $8-\mu \mathrm{m}$ pores. A total of $0.5 \times 10^{6}$ tumor cells per $\mathrm{ml}$ were placed in the upper chamber in serum-free medium. The lower chamber contained $10 \%$ serum. After $20 \mathrm{~h}$ incubation, the upper surface of the transwell membrane was gently wiped with a cotton swab to remove nonmigrating cells. Cells which had moved to the lower surface of the membrane were stained using haematoxylin and counted with a microscope (20x objective). The mean chemotaxis rate was calculated from five different fields. Chemotaxis of parental cell lines was set as $100 \%$. ${ }^{*} \mathrm{P} \leq 0.05$ vs. controls.

Immunohistochemical staining of integrin $\beta 1$. In non-malignant tissue samples, integrin $\beta 1$ was only visible in the basal layer of the urothelium. The medium staining score for normal urothelium was between 'negative' to 'weak' $(0.88 \pm 0.33)$. In bladder cancer samples, the mean integrin $\beta 1$ staining score was between 'moderate' and 'strong' (2.48 \pm 1.42$)$. There was no significant difference of integrin $\beta 1$ staining between low grade tumors or high grade tumors and no significant difference between non-muscle invasive tumors and muscle invasive tumors (Fig. 4).

Influence of blocking integrin $\beta 1$ on adhesion and chemotaxis. Functional blocking of integrin $\beta 1$ resulted in a reduced adhesion in 2 of 4 parental urothelial cancer cell lines (HT1376 and T24). In gemcitabine-resistant cells, adhesion was downregulated in 3 of 4 cell lines (gemcitabine-resistant sublines of HT1376, T24 and TCC-SUP). In cisplatin-resistant cells, adhesion was downregulated in all 4 tested cell lines (Fig. 5). We could not detect an influence on chemotaxis after blocking integrin $\beta 1$ (Fig. 6).

\section{Discussion}

In the present study, we used a well-established panel of urothelial cancer cell lines with acquired resistance to gemcitabine or cisplatin, the standard therapeutics for metastatic urothelial cancer of the bladder (2,3). Cell line panels seem to be necessary to reflect the heterogeneity of different patient-derived cancer cell lines. Although the complex scenario of metastatic colonization is not fully understood, there is strong evidence that alterations of tumor-matrix contact are necessary to allow motile crawling into the surrounding tissue (15).

In several cancer cells, resistance to gemcitabine seems to be connected with integrins and associated proteins (16-18). In addition, resistance to cytotoxic drugs and proliferation regulation was shown to be dependent on extracellular matrix proteins (19). In this study, acquisition of resistance to gemcitabine or cisplatin showed a changed adhesive behavior with some resistant sublines showing an enhanced adhesive behavior and other resistant sublines being less adhesive (Fig. 1). In contrast, the influence on chemotaxis was more uniform, with 5 of 8 sublines showing an enhanced chemotaxis and no subline with a significantly diminished chemotaxis after acquisition of resistance (Fig. 2). This is in line with Ploenes et al who reported about an enhanced chemotaxis in lung cancer cell lines with an increased chemoresistance (20).

Since integrins seem to be involved in the development of resistance to chemotherapy in bladder cancer (4) and alterations of integrin expression change adhesive and invasive behavior of bladder cancer cells (6), we aimed to elucidate the role of integrins in this context.

Integrin $\alpha 3$ might be involved in resistance acquisition, since it was upregulated in 3 of 4 gemcitabine-resistant and also in 3 of 4 cisplatin-resistant sublines in this study (Fig. 3). Litynska et al (21) tried to analyze the role of integrin $\alpha 3$ in bladder cancer by blocking its function. They described that adhesion was up- or downregulated after blocking integrin $\alpha 3$ depending on the tested cell line. The cell line specific effects that can be triggered after acquisition of resistance show the heterogeneity between independent cell lines and underline the importance of using a panel of cell lines for a better interpretation.

It was reported that integrin $\alpha 5$ contributes to a more malignant phenotype in urothelial bladder cancer (22). In our study, this integrin subunit was overexpressed in most of the tested chemoresistant sublines what might underline the more malignant phenotype of the chemoresistant sublines (Fig. 3). 

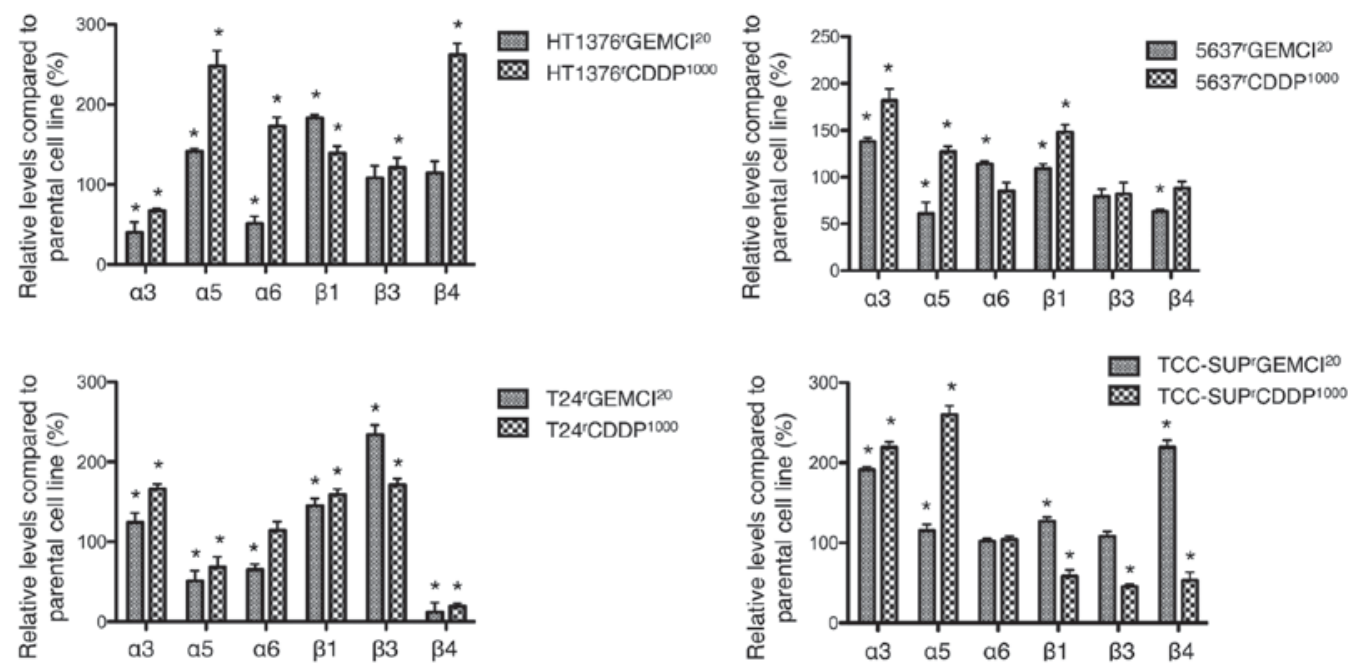

Figure 3. Flow cytometry analysis of integrin surface expression. Cells were washed in blocking solution and stained with specific monoclonal antibodies as listed in materials and methods. Mouse IgG1-PE or mouse IgG2a-PE antibodies were used as isotype controls. Fluorescence was analyzed using a FACScan flow cytometer. The relative fluorescence unit values are given in percentage difference to the parental cell lines. Parental cell lines were set as $100 \%$. One of three independent experiments is shown here. ${ }^{*} \mathrm{P} \leq 0.05$ vs. controls.
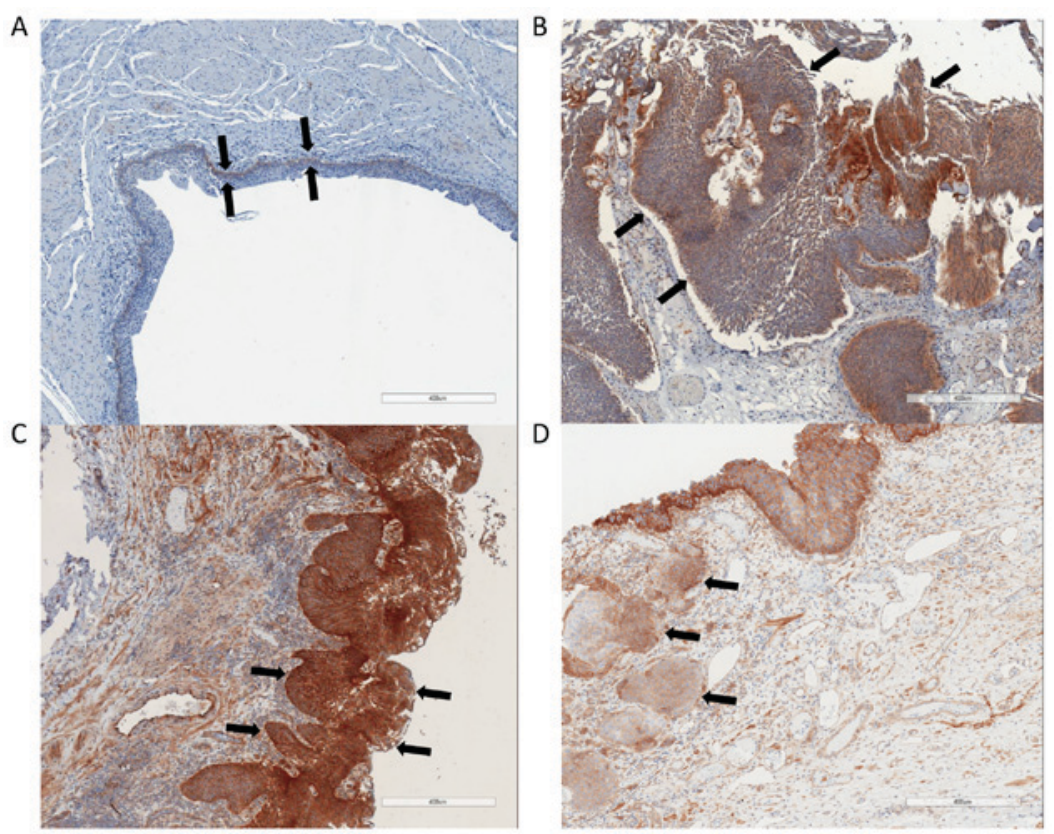

Figure 4. Expression of integrin $\beta 1$ in non-malignant urothelium and urothelial cancer. (A) Normal urothelium showed a negative or a weak expression of intergrin $\beta 1$ only in the basal cell layer. A higher integrin $\beta 1$ expression was visible in samples of (B) non invasive low grade urothelial cancer, (C) non invasive high grade cancer, and (D) muscle invasive high grade cancer. Immunostaining of 4 representative tissue samples.

We observed that most chemoresistant sublines showed a diminished expression of integrin $\beta 4$ compared to their parental counterparts (Fig. 3). Therefore, a downregulation of integrin $\beta 4$ could be connected with a more malignant behavior. This is in line with reports that an overexpression of integrin $\beta 4$ inhibits growth and migration in bladder cancer cell lines and plays an anti-tumoral role $(23,24)$.

In all gemcitabine-resistant and in 3 of 4 cisplatin-resistant sublines, surface expressed integrin $\beta 1$ was upregulated compared to parental cell lines (Fig. 3). Since chemotaxis was frequently enhanced after acquisition of resistance, these results might support the conclusions of Chakraborty et al (25) who postulated that blockade of $\beta 1$-integrin with a specific antibody could result in alteration of multiple signaling pathways related to adhesion and migration. Interestingly, Zhang and coworkers showed that they could reverse chemoresistance to mitomycin c by blocking integrin $\beta 1$ (4). Integrin $\beta 1$ was overexpressed in most of the tested sublines and it was reported to contribute to a more malignant phenotype in urothelial bladder cancer $(4,25)$. We could confirm in this study that overexpression of integrin $\beta 1$ is associated with a malignant phenotype since we detected a stronger expression in malignant tissue samples compared to normal urothelium. Nevertheless, there was no different expression comparing low 

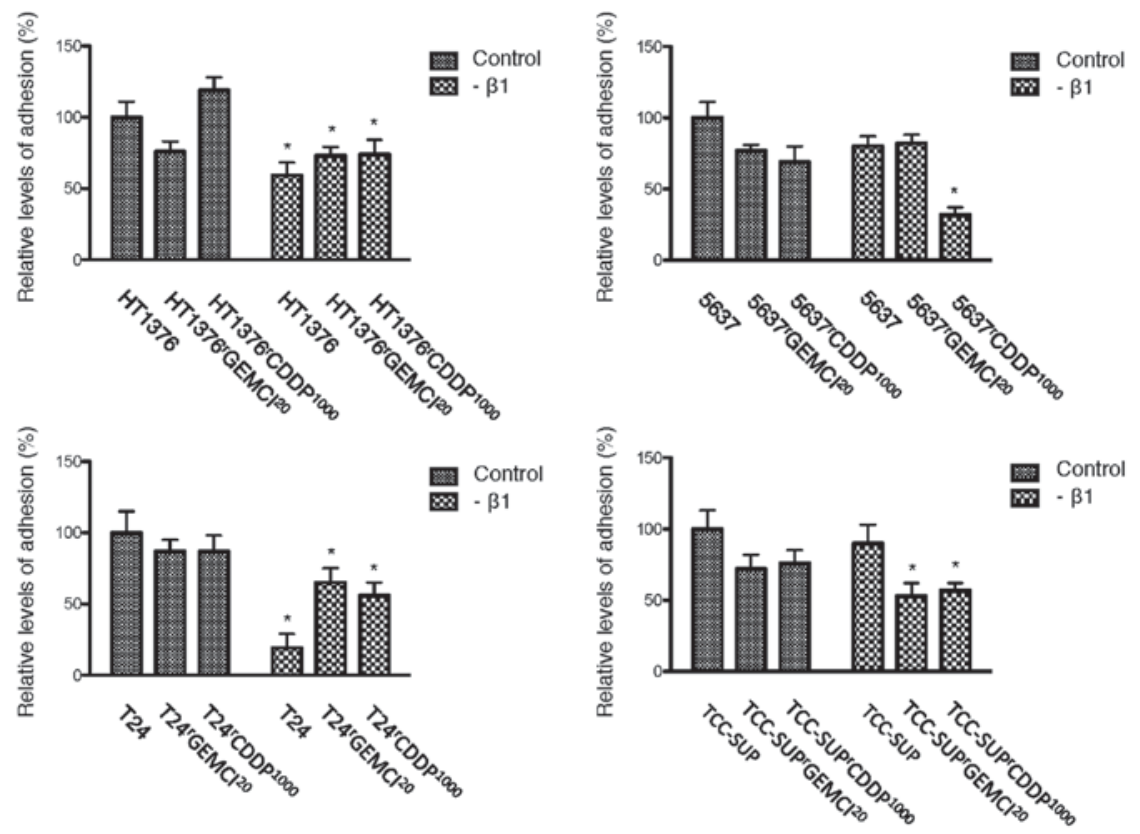

Figure 5. Influence on adhesion after blocking integrin $\beta 1$. Bladder cancer cell lines were preincubated for 60 min with a monoclonal anti-integrin $\beta 1$ blocking antibody $(20 \mathrm{mg} / \mathrm{l})$. Controls remained untreated. Cells were then subjected to the adhesion assay as indicated. Untreated parental cells were set as $100 \%$. ${ }^{*} \mathrm{P} \leq 0.05$ vs. controls.
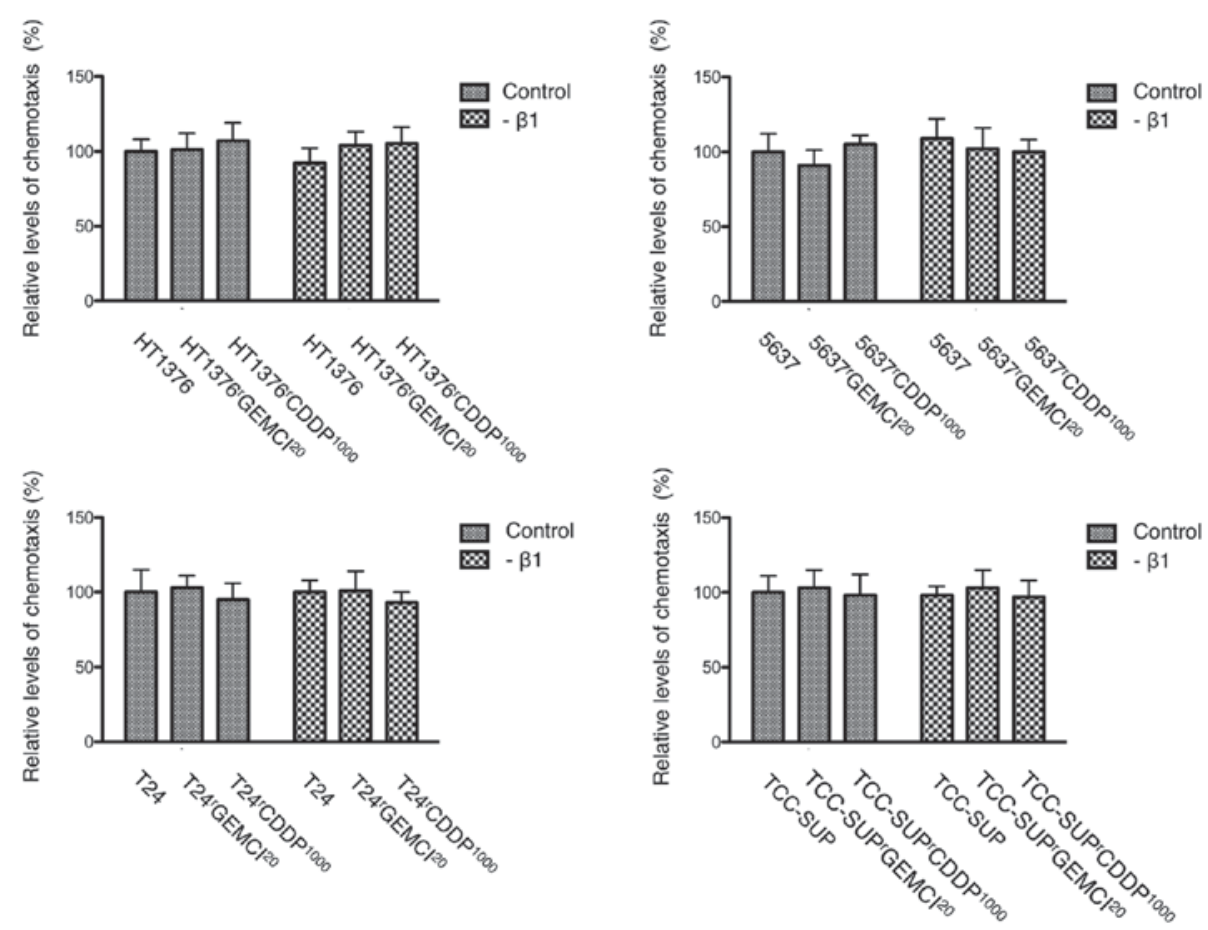

Figure 6. Influence on chemotaxis after blocking integrin $\beta 1$. Bladder cancer cell lines were preincubated for 60 min with a monoclonal anti-integrin $\beta 1$ blocking antibody $(20 \mathrm{mg} / \mathrm{l})$. Controls remained untreated. Cells were then subjected to the chemotaxis assay as indicated. Untreated parental cells were set as $100 \%$. $\mathrm{P} \leq 0.05$ vs. controls.

grade with high grade tumors or between non-muscle invasive bladder cancer and muscle invasive bladder cancer (Fig. 4).

To further analyze the role of integrin $\beta 1$, we suppressed the function of integrin $\beta 1$ and meassured adhesion and chemotaxis afterwards. There was an influence on adhesion after blocking integrin $\beta 1$ with a reduced adhesion in 2 of 4 parental and 3 of 4 gemcitabine-resistant sublines. In cisplatin-resistant cells, adhesion was even downregulated in all 4 tested cell lines (Fig. 5).

We could not show an influence on chemotaxis after blocking integrin $\beta 1$ (Fig. 6). If there is no influence on chemotaxis or if the used transwell migration assay is not able to reflect the impact on chemotaxis is not clear. An explanation for the latter might be that effects that influence invasion after 
blocking integrin $\beta 1$ are delayed and therefore not detectable with the used transwell migration assay.

Discussing the role of different integrins and the influence on adhesive and invasive behavior, we should be aware that differentially guided adhesive behavior of different tumor cell lines has been previously observed (21). Blocking integrin $\beta 1$ inhibited cell-matrix interactions in HCV29 and BC3726 cell lines, whereas binding of the bladder cancer cell lines T24 and Hu456 was enhanced (21). Each cell line therefore may possess a characteristic receptor set and long-term treatment with chemotherapy may influence integrin subfamilies differently. Therefore systematic analysis of cell line panels is fundamental (6).

We did not investigate the relevance of each integrin member in detail that was used here. To provide a complete picture of the role of integrin subtypes in gemcitabine- and cisplatin-resistant bladder cancer ongoing studies are necessary. Particularly, blocking experiments using integrins $\alpha 3$, $\alpha 5$, and $\beta 4$ would be of interest. In addition, these findings are limited to bladder cancer cell lines and bladder tissue. The role of integrins in chemoresistant bladder cancer should be further evaluated in vivo in an animal model.

Overall, evidence is presented here that acquired resistance to gemcitabine or cisplatin frequently enhances chemotaxis, what might be a surrogate for an increased invasive behavior in chemoresistant bladder cancer cell lines. Since overexpression of integrin $\beta 1$ seems to be frequently upregulated in chemoresistant urothelial bladder cancer cell lines, further in vivo studies should evaluate downregulation of integrin $\beta 1$ as a potential therapeutic target especially in chemotherapy refractory cases.

\section{Acknowledgements}

The work was supported by the charity Hilfe für krebskranke Kinder Frankfurt e.V., its trust Frankfurter Stiftung für krebskranke Kinder, the Patenschaftsmodell program of the University Hospital Frankfurt and the Kent Cancer Trust.

\section{References}

1. Siegel RL, Miller KD and Jemal A: Cancer statistics, 2016. CA Cancer J Clin 66: 7-30, 2016.

2. Pectasides D, Pectasides M and Economopoulos T: Systemic chemotherapy in locally advanced and/or metastatic bladder cancer. Cancer Treat Rev 32: 456-470, 2006.

3. von der Maase H, Sengelov L, Roberts JT, Ricci S, Dogliotti L, Oliver T, Moore MJ, Zimmermann A and Arning M: Long-term survival results of a randomized trial comparing gemcitabine plus cisplatin, with methotrexate, vinblastine, doxorubicin, plus cisplatin in patients with bladder cancer. J Clin Oncol 23: 4602-4608, 2005.

4. Zhang CJ, Shen ZJ, Pan CW, Zhong S, Li T and Zhang MG: Engagement of integrin $\beta 1$ induces resistance of bladder cancer cells to mitomycin-C. Urology 79: 638-643, 2012.

5. Canel M, Serrels A, Frame MC and Brunton VG: E-cadherin-integrin crosstalk in cancer invasion and metastasis. J Cell Sci 126: 393-401, 2013.

6. Juengel E, Meyer dos Santos S, Schneider T, Makarevic J, Hudak L, Bartsch G, Haferkamp A, Wiesner C and Blaheta RA: HDAC inhibition suppresses bladder cancer cell adhesion to collagen under flow conditions. Exp Biol Med (Maywood) 238: 1297-1304, 2013.

7. Danen EH: Integrins: Regulators of tissue function and cancer progression. Curr Pharm Des 11: 881-891, 2005.
8. Yamasaki M, Soda S, Sakakibara Y, Suiko M and Nishiyama K: The importance of 1,2-dithiolane structure in $\alpha$-lipoic acid for the downregulation of cell surface $\beta 1$-integrin expression of human bladder cancer cells. Biosci Biotechnol Biochem 78: 1939-1942, 2014.

9. Behnsawy HM, Miyake H, Abdalla MA, Sayed MA, Ahmed Ael-F and Fujisawa M: Expression of integrin proteins in non-muscle-invasive bladder cancer: Significance of intravesical recurrence after transurethral resection. BJU Int 107: 240-246, 2011.

10. Sharma SV, Haber DA and Settleman J: Cell line-based platforms to evaluate the therapeutic efficacy of candidate anticancer agents. Nat Rev Cancer 10: 241-253, 2010.

11. Domingo-Domenech J, Vidal SJ, Rodriguez-Bravo V, Castillo-Martin M, Quinn SA, Rodriguez-Barrueco R, Bonal DM, Charytonowicz E, Gladoun N, de la Iglesia-Vicente J, et al: Suppression of acquired docetaxel resistance in prostate cancer through depletion of notch- and hedgehog-dependent tumor-initiating cells. Cancer Cell 22: 373-388, 2012.

12. Vallo S, Michaelis M, Rothweiler F, Bartsch G, Gust KM, Limbart DM, Rödel F, Wezel F, Haferkamp A and Cinatl J Jr: Drug-resistant urothelial cancer cell lines display diverse sensitivity profiles to potential second-line therapeutics. Transl Oncol 8: 210-216, 2015.

13. Mani J, Vallo S, Rakel S, Antonietti P, Gessler F, Blaheta R, Bartsch G, Michaelis M, Cinatl J, Haferkamp A and Kögel D: Chemoresistance is associated with increased cytoprotective autophagy and diminished apoptosis in bladder cancer cells treated with the BH3 mimetic (-)-Gossypol (AT-101). BMC Cancer 15: 224, 2015.

14. Michaelis M, Rothweiler F, Barth S, Cinatl J, van Rikxoort M, Löschmann N, Voges Y, Breitling R, von Deimling A, Rödel F, et al: Adaptation of cancer cells from different entities to the MDM2 inhibitor nutlin-3 results in the emergence of p53-mutated multi-drug resistant cancer cells. Cell Death Dis 2: e243, 2011.

15. Yilmaz M and Christofori G: Mechanisms of motility in metastasizing cells. Mol Cancer Res 8: 629-642, 2010.

16. Huanwen W, Zhiyong L, Xiaohua S, Xinyu R, Kai W and Tonghua L: Intrinsic chemoresistance to gemcitabine is associated with constitutive and laminin-induced phosphorylation of FAK in pancreatic cancer cell lines. Mol Cancer 8: 125, 2009.

17. Jia Z: Role of integrin-linked kinase in drug resistance of lung cancer. Onco Targets Ther 8: 1561-1565, 2015.

18. Duxbury MS, Ito H, Benoit E, Waseem T, Ashley SW and Whang EE: RNA interference demonstrates a novel role for integrin-linked kinase as a determinant of pancreatic adenocarcinoma cell gemcitabine chemoresistance. Clin Cancer Res 11: 3433-3438, 2005.

19. Miyamoto H, Murakami T, Tsuchida K, Sugino H, Miyake H and Tashiro S: Tumor-stroma interaction of human pancreatic cancer: Acquired resistance to anticancer drugs and proliferation regulation is dependent on extracellular matrix proteins. Pancreas 28: 38-44, 2004.

20. Ploenes T, Scholtes B, Krohn A, Burger M, Passlick B, Müller-Quernheim J and Zissel G: CC-chemokine ligand 18 induces epithelial to mesenchymal transition in lung cancer A549 cells and elevates the invasive potential. PLoS One 8: e53068, 2013

21. Lityńska A, Przybyło M, Pocheć E and Laidler P: Adhesion properties of human bladder cell lines with extracellular matrix components: The role of integrins and glycosylation. Acta Biochim Pol 49: 643-650, 2002.

22. Saito T, Kimura M, Kawasaki T, Sato S and Tomita Y: Correlation between integrin alpha 5 expression and the malignant phenotype of transitional cell carcinoma. Br J Cancer 73: 327-331, 1996.

23. Kim SY, Bachman NJ, Nair TS, Goldsmith S, Liebert M, Grossman HB, Lomax MI and Carey TE: Beta 4 integrin transfection of UM-UC-2 (human bladder carcinoma) cells: Stable expression of a spontaneous cytoplasmic truncation mutant with rapid loss of clones expressing intact beta 4. Cancer Res 57: 38-42, 1997.

24. Harabayashi T, Kanai Y, Yamada T, Sakamoto M, Ochiai A, Kakizoe T, Koyanagi T and Hirohashi S: Reduction of integrin beta4 and enhanced migration on laminin in association with intraepithelial spreading of urinary bladder carcinomas. J Urol 161: 1364-1371, 1999.

25. Chakraborty A, White SM and Guha S: Granulocyte colony-stimulating receptor promotes beta1-integrin-mediated adhesion and invasion of bladder cancer cells. Urology 68: 208-213, 2006. 